\title{
The influence of Service Quality on Customer Satisfaction at Workshop PT Wahana Sun Motor Branch Puri Anjasmoro
}

\author{
Diaz Ardiani, Noor Suroija*, Eva Purnamasari \\ Applied Business Administration, State Polytechnic of Semarang, Indonesia
}

\begin{abstract}
This study aimed to determine the influence of service quality on customer satisfaction at workshop PT Wahana Sun Motor Branch Office Puri Anjasmoro. This research used the dimensions of service quality, namely : tangible, reliability, responsiveness, assurance, and empathy to customer satisfaction. Data analysis that used were instrument test, classical assumption test, multiple linear regression analysis, and hypothesis test. The sample that used in this study were 100 respondents that choosen using probability sampling method. Hypothesis test result indicate that tangible, reliability, responsiveness, assurance, and empathy influencing the customer satisfaction. Furthermore, tangible, reliability, responsiveness, assurance, and empathy simultaneously influencing the customer satisfaction. The results of the coefficient of determination indicate that tangible, reliability, responsiveness, assurance, and empathy influencing the customer satisfaction by $60,3 \%$ and the remaining $39,7 \%$ of customer satisfaction is influenced by other factors which were not observed in this study.
\end{abstract}

Keywords: Service Quality, Dimensions of Quality of Service, Customer Satisfaction. 


\title{
Pengaruh Kualitas Pelayanan terhadap Kepuasan Pelanggan pada Bengkel PT Wahana Sun Motor Cabang Puri Anjasmoro
}

\begin{abstract}
Abstrak
Tujuan dari penelitian ini adalah untuk mengetahui pengaruh kualitas pelayanan terhadap kepuasan pelanggan pada bengkel PT Wahana Sun Motor Cabang Puri Anjasmoro. Penelitian ini menggunakan dimensi kualitas pelayanan yaitu tangible, reliability, responsiveness, assurance, dan empathy. Analisis data yang digunakan antara lain, uji instrumen, uji asumsi klasik, analisis regresi linier berganda dan uji hipotesis. Penelitian ini dilakukan terhadap 100 orang responden dengan menggunakan metode probability sampling. Hasil uji hipotesis menunjukkan bahwa secara parsial tangible, reliability, responsiveness, assurance, dan empathy berpengaruh terhadap kepuasan pelanggan. Secara simultan tangible, reliability, responsiveness, assurance, dan empathy berpengaruh terhadap kepuasan pelanggan. Hasil koefisien determinasi menunjukkan bahwa tangible, reliability, responsiveness, assurance, dan empathy berpengaruh terhadap kepuasan pelanggan yakni sebesar 60,3\% dan sisanya 39,7\% kepuasan pelanggan dipengaruhi oleh faktor lain yang tidak diteliti dalam peneltian ini.
\end{abstract}

Kata kunci: Kualitas Pelayanan, Dimensi Kualitas Pelayanan, Kepuasan Pelanggan. 


\section{PENDAHULUAN}

Sarana transportasi menjadi kebutuhan mendasar bagi masyarakat Indonesia dikarenakan wilayah di Indonesia berbentuk kepulauan yang sangat luas dan sebagaian besar wilayahnya dihubungkan melalui jalur darat. Hal tersebut menjadi salah satu faktor yang menyebabkan permintaan kendaraan di Indonesia yang semakin meningkat. Kecermatan sebuah perusahaan dapat dilihat dengan cara mengamati, memahami, dan menghadirkan keinginan pelanggan agar dapat menjaga kelangsungan hidup perusahaan. Agar dapat menarik hati pelanggan, perusahaan otomotif tidak hanya menjual mobil saja, akan tetapi menyediakan jasa servis kendaraan guna memenuhi kebutuhan pelanggan akan servis tersebut. Pemberian layanan servis tidak terlepas dari bagaimana cara perusahaan dapat memberikan pelayanan yang baik kepada pelanggan. Kualitas pelayanan baik yang diberikan kepada pelanggan dapat mempengaruhi tingkat kepuasan pelanggan terhadap penggunaan produk/jasa tersebut.

Menurut Naderian dan Rohaizat, (2015) tingkat tinggi kualitas layanan yang dirasakan pelanggan akan memberikan tingkat kepuasan kepada pelanggan, yang berdampak positif terhadap loyalitas pelanggan. Menurut Nguyen, Quang dkk., (2018) mendefinisikan bahwa kualitas pelayanan sebagai perbedaan antara persepsi konsumen terhadap layanan yang ditawarkan oleh perusahaan tertentu dan harapan mereka tentang perusahaan yang menawarkan layanan tersebut. Menurut Nguyen, Quang dkk., (2018) mengatakan bahwa Kualitas pelayanan juga dianggap sebagai atribut yang dirasakan berdasarkan pengalaman dari pelanggan mengenai layanan yang pelanggan rasakan selama proses pengiriman layanan. Melalui teori-teori tersebut dapat disimpulkan bahwa pelanggan akan merasa puas apabila pelanggan mengalami dan menerima pelayanan yang sesuai dengan harapan pelanggan. Nguyen, Quang dkk., (2018) telah membuktikan bahwa Jika harapan lebih tinggi dari kinerja maka persepsi kualitas akan lebih rendah dari memuaskan dan karenanya ketidakpuasan pelanggan terjadi.

Kolter dan Gary (2017:31) menyatakan bahwa pelanggan yang puas akan membeli lagi dan memberi tahu orang lain tentang pengalaman baik mereka. Pelanggan yang tidak puas sering beralih ke pesaing dan meremehkan produk lain. Tidak hanya kualitas layanan, pengalaman baik yang dirasakan pelanggan merupakan suatu hal yang penting, apabila pelanggan puas mereka akan menceritakan pengalaman menyenangkan apa saja yang dirasakan kepada orang lain. Kepuasan pelanggan dibidang jual beli otomotif (mobil) dapat berlangsung beberapa tahap yaitu pra pembelian, pada saat pembelian dan pasca pembelian. Pra pembelian dapat berupa pelayanan yang baik saat melakukan penawaran kepada pelanggan, memberikan informasi tentang produk dengan cara baik dan benar. Saat pembelian bisa berupa pelayanan karyawan saat melakukan DO (Deal Order) mobil, pengantaran mobil sesuai dengan waktu yang dijanjikan. Pasca pembelian berupa feedback akan pelayanan yang diberikan, ketersediaan bengkel servis mobil dan juga sparepart yang lengkap dan resmi.

Salah satu perusahan yang berjalan dalam bidang otomotif adalah PT Wahana Sun Motor Cabang Puri Anjasmoro yang merupakan sebuah dealer cabang yang bergerak dibidang penjualan mobil dengan merek Nissan dan Datsun sebagai produknya yang memiliki beberapa tipe dan jasa servis. PT Wahana Sun Motor Cabang Puri Anjasmoro dalam usahanya memberikan kepuasan pelanggan melakukan banyak upaya yang berorientasi kepada peningkatan kepuasan pelanggan, namun usaha tersebut masih diragukan karena pada tahun 2019 tingkat presentase nilai ketidakpuasan pelanggan masih mengalami fluktuasi. Customer Relation Officer merupakan bagian yang menangani dan melakukan feedback 
kepada pelanggan mengenai kepuasan pelanggan.

\section{Tinjauan Pustaka}

\section{Pemasaran}

Kotler dan Kevin (2018:27) menyatakan Pemasaran adalah aktivitas, seperangkat lembaga, dan proses untuk menciptakan, berkomunikasi, memberikan dan bertukar penawaran yang memiliki nilai pelanggan, klien, mitra, dan masyarakat luas. Kotler dkk. (2017:4) menyatakan definisi pemasaran adalah kegiatan mengelola hubungan pelangan yang menguntungkan. Tujuan ganda pemasaran adalah untuk menarik pelanggan baru dengan menjanjikan nilai pelanggan dan mempertahankan pelanggan dengan memberikan kepuasan.

Jasa

Menurut Wirtz, Jochen dkk., (2017:14), jasa merupakan tindakan melayani, membantu, atau mendapatkan manfaat melakukan pemeliharaan untuk kesejahteraan atau keuntungan dari yang lain. Tjiptono dan Gregorius, (2016:25) secara garis besar karakteristik jasa terdiri dari Intangibility, Inseparability, Variability/Heterogeneity dan Perishability.

\section{Kepuasan Pelanggan}

Kottler dan Kevin (2018:138) Kepuasan pelanggan adalah perasaan senang atau kecewa yang didapatkan seseorang dari membandingkan antara kinerja (atau hasil) produk yang dipersepsikan dan ekspektasinya. Seorang pelanggan puas atau tidak, sangat tergantung pada kinerja produk dibandingkan ekspektasi pelanggan bersangkutan dan apakah sang pelanggan menginterpretasikan adanya deviasi atau gap di antara kinerja dan ekspektasi tersebut.

\section{Indikator Kepuasan Pelanggan}

Menurut Irawan (2008:37) terdapat 4 (empat) dimensi kepuasan pelanggan antara lain:

a. Perasaan puas (dalam arti puas akan produk dan pelayanannya)
Ungkapan perasaan puas atau tidak puas dari pelanggan saat menerima pelayanan yang baik dan produk yang berkualitas dari perusahaan.

b. Selalu membeli produk

Pelanggan akan tetap memakai dan terus membeli suatu produk apabila tercapainya harapan yang mereka inginkan.

c. Akan merekomendasikan kepada orang lain

Pelanggan yang merasa puas setelah memakai suatu produk atau jasa akan menceritakannya kepada orang lain serta mampu menciptakan pelanggan baru bagi suatu perusahaan.

d. Terpenuhinya harapan pelanggan setelah membeli produk

Sesuai atau tidaknya kualitas suatu produk atau jasa pasca pembelian suatu produk dengan harapan yang diinginkan pelanggan.

\section{Kualitas Pelayanan}

Kualitas pelayanan adalah perbedaan antara persepsi konsumen terhadap layanan yang ditawarkan oleh perusahaan tertentu dan harapan mereka tentang perusahaan yang menawarkan layanan tersebut (Nguyen, Quang dkk., 2018). Service Performance (SERVPERF) merupakan alat ukur yang dianggap lebih tepat untuk mengukur kepuasan pelanggan terhadap layanan yang didapatkan. Service Performance merupakan alat ukur terhadap kualitas layanan yang dikembangkan dari Service Quality (SERVQUAL). Kualitas Pelayanan dapat diukur dengan menggunakan lima dimensi. Kelima dimensi tersebut menurut Wahyuni dkk. (2015:34).

a. Tangible (Bukti Fisik)

Berkenaan dengan daya tarik fasilitas, perlengkapan dan materi layanan digunakan perusahaan, serta penampilan karyawan. Indikator dari tangible (bukti fisik) terdiri dari fasilitas reservasi yang lengkap, ruang tunggu yang nyaman, dan penampilan karyawan. 
b. Reliability (Kehandalan)

Kemampuan perusahaan untuk memberikan layanan yang akurat sejak pertama kali tanpa membuat kesalahan apapun dan menyampaikan jasanya sesuai dengan waktu yang disepakati. Indikator dari reliability (kehandalan) terdiri dari kesesuaian layanan yang dijanjikan, ketepatan pelayanan, dan ketepatan informasi.

c. Responsiveness (Daya Tanggap)

Kesediaan dan kemampuan karyawan dalam membantu pelanggan dan merespon permintaan mereka, serta mengkonfirmasikan kapan saja jasa yang akan diberikan. Indikator dari responsiveness (daya tanggap) terdiri dari kecepatan pelayanan, memberikan informasi yang jelas, dan menangani keluhan pelanggan. d. Assurance (Jaminan)

Perilaku karyawan yang mampu menumbuhkan kepercayaan pelanggan terhadap perusahaan, dan perusahaan bisa menciptakan rasa aman bagi para pelanggannya. Indikator assurance (jaminan) terdiri dari keamanan service, keamanan transaksi pembayaran, dan jaminan garansi.

e. Empathy (Empati)

Perusahaan memahami masalah pelanggan dan bertindak demi kepentingan pelanggan, serta memberikan perhatian personal kepada pelanggan dan memiliki jam operasional yang nyaman. Indikator empathy (empati) terdiri dari karyawan bersikap ramah, kemudahan berkomunikasi, dan karyawan bersikap sabar.

\section{Kerangka Pemikiran Teoritis}

\section{Gambar 1. Kerangka Pemikiran Teoritis}

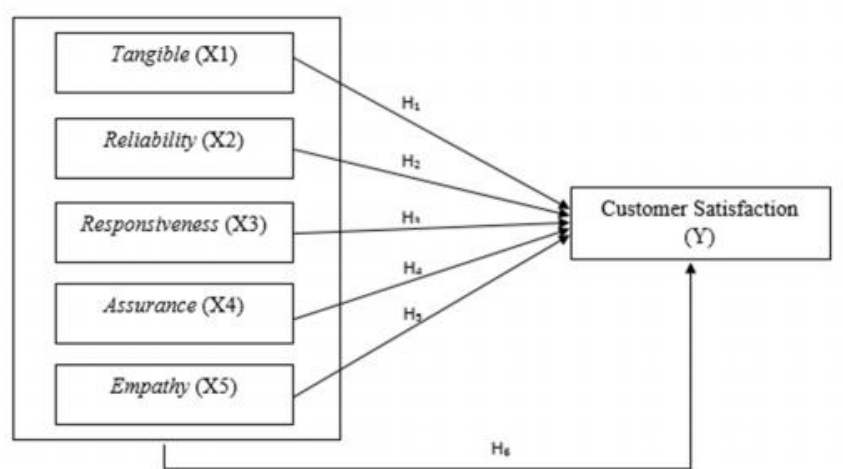

Sumber: Permansari (2013), Alaan (2016), Panjaitan and Ai Lili (2016)

\section{Hipotesis Penelitian}

Berdasarkan teori dan kerangka pemikiran di atas, maka hipotesis penelitian adalah sebagai berikut:

a. Ho1: Tidak terdapat pengaruh antara tangible terhadap kepuasan pelanggan pada bengkel PT Wahana Sun Motor Cabang Puri Anjasmoro

Ha1: Terdapat pengaruh antara tangible terhadap kepuasan pelanggan pada bengkel PT Wahana Sun Motor Cabang Puri Anjasmoro b. Ho2: Tidak terdapat pengaruh antara reliability terhadap kepuasan pelanggan pada bengkel PT Wahana Sun Motor Cabang Puri Anjasmoro

$\mathrm{Ha}$ 2: Terdapat pengaruh antara reliability terhadap kepuasan pelanggan pada bengkel PT Wahana Sun Motor Cabang Puri Anjasmoro

c. Ho3: Tidak terdapat pengaruh antara responsiveness terhadap kepuasan pelanggan pada bengkel PT Wahana Sun Motor Cabang Puri Anjasmoro 
Ha3: Terdapat pengaruh antara responsiveness terhadap kepuasan pelanggan pada bengkel PT Wahana Sun Motor Cabang Puri Anjasmoro

d. Ho4: Tidak terdapat pengaruh antara assurance terhadap kepuasan pelanggan pada bengkel PT Wahana Sun Motor Cabang Puri Anjasmoro

Ha4: Terdapat pengaruh antara assurance terhadap kepuasan pelanggan pada bengkel PT Wahana Sun Motor Cabang Puri Anjasmoro

e. Ho5: Tidak terdapat pengaruh antara empathy terhadap kepuasan pelanggan pada bengkel PT Wahana Sun Motor Cabang Puri Anjasmoro

Ha5: Terdapat pengaruh antara empathy terhadap kepuasan pelanggan pada bengkel PT Wahana Sun Motor Cabang Puri Anjasmoro

f. Ho6: Tidak terdapat pengaruh antara tangible, reliability, responsiveness, assurance dan empathy secara bersamasama terhadap kepuasan pelanggan pada bengkel PT Wahana Sun Motor Cabang Puri Anjasmoro

Ha6: Terdapat pengaruh antara tangible, reliability, responsiveness, assurance dan empathy secara bersama-sama terhadap kepuasan pelanggan pada bengkel PT Wahana Sun Motor Cabang Puri Anjasmoro.

\section{METODE PENELITIAN}

Populasi yang digunakan adalah semua pelanggan bengkel PT Wahana Sun Motor Cabang Puri Anjasmoro yang sudah pernah menggunakan jasa servis Bengkel PT Wahana Sun Motor Cabang Puri Anjasmoro. Jumlah populasi pelanggan dalam 1 (satu) tahun 2019 sebanyak 19.038 pelanggan. Sedangkan sampel yang digunakan dalam penelitian ini berjumlah 100 responden yaitu pelanggan bengkel PT Wahana Sun Motor Cabang Puri Anjasmoro, dengan teknik sampling yang digunakan dalam penelitian ini mengggunakan insidental sampling.

\section{Metode Analisis}

Skala interval dalam penelitian ini menggunakan Agree-Disagree Scale dengan rentang nilai dari angka 1-10. Melalui data yang dikumpulkan terdapat beberapa metode analisis yang digunakan dalam penelitian ini adalah:

\section{a. Analisis Deskripsi Persepsi Responden}

Teknik analisis indeks digunakan untuk mendapatkan gambaran deskriptif responden atas item-item pertanyaan yang diajukan (Ferdinand, 2014). Angka jawaban responden dimulai dari skor minimum 1 dan maksimum 10.

\section{b. Uji Validitas dan Reliabilitas}

Uji validitas digunakan untuk mengukur sah atau valid tidaknya suatu kuesioner. Suatu kuesioner dikatakan valid jika pertanyaan pada kuesioner mampu untuk mengungkapkan sesuatu yang akan diukur oleh kuesioner tersebut (Ghozali, 2018:51). Uji signifikansi dilakukan dengan membandingkan nilai $\mathrm{r}_{\mathrm{htiung}}$ dengan $r_{\text {tabel }}$ untuk degree of freedom (df) $=\mathrm{n}-2$, dalam hal ini $\mathrm{n}$ adalah jumlah sampel. Jika $r_{\text {hitung }}>r_{\text {tabel }}$ dan nilai positif maka butir atau pertanyaan atau indikator tersebut dinyatakan valid. Reliabilitas adalah alat untuk mengukur suatu kuesioner yang merupakan indikator dari variabel atau konstruk. Suatu kuesioner dikatakan reliabel atau handal jika jawaban seseorang terhadap pernyataan adalah konsisten atau stabil dari waktu ke waktu (Ghozali, 2018:45). Menurut Ghozali (2018:25) suatu konstruk atau variabel dikatakan reliabel jika memberikan nilai Cronbach's Alpha > 0,70 .

\section{c. Uji Asumsi Klasik}

Dalam analisis regresi linier berganda perlu menghindari penyimpangan asumsi klasik agar tidak timbul masalah dalam penggunaan analisis tersebut. Uji Asumsi Klasik terdiri dari Uji Multikolinearitas, Uji Heteroskedastisitas, Uji Normalitas dan Uji Linearitas. Ghozali (2018:107) menjelaskan, bahwa uji multikolinearitas 
bertujuan untuk menguji apakah model regresi ditemukan adanya korelasi antar variabel bebas (independen). Uji heteroskedastisitas bertujuan menguji apakah dalam sebuah model regresi, terjadi ketidaksamaan variance dari residual satu pengamatan ke pengamatan lain. Uji normalitas bertujuan untuk menguji apakah dalam model regresi, variabel pengganggu atau residual memiliki distribusi normal. Uji linearitas bertujuan untuk melihat spesifikasi model yang digunakan sudah benar atau belum (Ghozali, 2018:167).

\section{d. Uji Regresi Linear Berganda}

Dalam penulisan penelitian ini menggunakan model analisis regresi linier berganda (Multiple Regression Analysis Model). Analisis regresi pada dasarnya adalah studi mengenai ketergantungan variabel dependen dengan 1 (satu) atau lebih variabel independen (Ghozali, 2018:95). Dalam analisis regresi, selain mengukur kekuatan hubungan antara 2 (dua) variabel atau lebih, juga menunjukkan arah hubungan antara variabel dependen dengan variabel independen (Ghozali, 2018:96). Pertimbangan dipergunakan uji statistik ini karena penelitian ini mempergunakan lebih dari satu variabel bebas yang meliputi Tangible, Reliability, Responsiveness, Assurance, Empathy.

e. Uji Hipotesis

Uji hipotesis dalam penelitian ini terdapat 3 (tiga) uji, yaitu:

\section{1) Uji Koefisien Determinasi $\left(\mathbf{R}^{\mathbf{2}}\right)$}

Koefisien determinasi (Adjusted $R$ Square) pada dasarnya mengukur seberapa jauh kemampuan model dalam menerangkan variasi dependen..

2) Uji Signifikansi Simultan (Uji F)

Ghozali (2018:98) menjelaskan, bahwa uji statistik $\mathrm{F}$ digunakan untuk mengetahui variabel independen secara bersama-sama atau simultan mempengaruhi variabel dependen.

\section{3) Uji Signifikansi Parsial (Uji T)}

Menurut Ghozali (2018:98) menjelaskan, uji $\mathrm{T}$ pada dasarnya menunjukkan seberapa jauh pengaruh satu variabel penjelas/independen secara individual dalam menerangkan variasi variabel dependen.

\section{HASIL DAN PEMBAHASAN}

a. Analisis Deskripsi Persepsi Responden Nilai indeks persepsi pelanggan bengkel PT Wahana Sun Motor Cabang Puri Anjasmoro terhadap variabel-variabel penelitian sebagai berikut:

1) Tangible

Rata-rata untuk keseluruhan indikator variabel tangible adalah sebesar 81,13 dengan indikator tertinggi adalah penampilan karyawan (X1.3) dengan nilai indeks sebesar 83,10.

2) Reliability

Rata-rata untuk keseluruhan indikator variabel reliability adalah sebesar 79,23 dengan indikator tertinggi adalah ketepatan pelayanan (X2.2) dengan nilai indeks sebesar 80,00.

3) Responsiveness

Rata-rata untuk keseluruhan indikator variabel responsiveness adalah sebesar 80,13 dengan indikator tertinggi adalah menangani keluhan pelanggan (X3.3) dengan nilai indeks sebesar 82,60.

4) Assurance

Rata-rata untuk keseluruhan indikator variabel assurance adalah sebesar 82,37 dengan indikator tertinggi adalah jaminan garansi (X4.3) dengan nilai indeks sebesar 82,60.

5) Empathy

Rata-rata untuk keseluruhan indikator variabel empathy adalah sebesar 82,03 dengan indikator tertinggi adalah kemudahan berkomunikasi (X5.2) dengan nilai indeks sebesar 82,90 . 
6) Kepuasan Pelanggan

Rata-rata untuk keseluruhan indikator variabel kepuasan pelanggan adalah sebesar 81,47 dengan indikator tertinggi adalah kepuasan pelanggan keseluruhan (Y1.1) dengan nilai indeks sebesar 81,90.

\section{b. Uji Validitas dan Uji Reliabilitas}

1) Uji Validitas

Perhitungan uji validitas dilakukan dengan program SPSS versi 25, dengan menggunakan 30 responden dalam menguji validitas dan reliabilitas. Penelitian ini menggunakan $r$ tabel dengan tingkat kesalahan sebesar 5\% dan dengan nilai sebesar $\mathrm{df}=30-2=28$.

Tabel 1. Uji Validitas

\begin{tabular}{|c|c|c|c|c|c|}
\hline No & Variabel Indikator & $\begin{array}{c}\text { Item } \\
\text { Pertanyaan }\end{array}$ & $\begin{array}{l}\text { Nilai R } \\
\text { Hitung }\end{array}$ & $\begin{array}{c}\text { Nilai R } \\
\text { Tabel }\end{array}$ & Keterangan \\
\hline \multirow[t]{3}{*}{1.} & \multirow[t]{3}{*}{ Tangible } & $\mathrm{X} 1.1$ & 0,888 & 0,361 & Valid \\
\hline & & $\mathrm{X} 1.2$ & 0,863 & 0,361 & Valid \\
\hline & & $\mathrm{X} 1.3$ & 0,912 & 0,361 & Valid \\
\hline \multirow[t]{3}{*}{2.} & \multirow[t]{3}{*}{ Reliability } & $\mathrm{X} 2.1$ & 0,908 & 0,361 & Valid \\
\hline & & $\mathrm{X} 2.2$ & 0,898 & 0,361 & Valid \\
\hline & & $\mathrm{X} 2.3$ & 0,900 & 0,361 & Valid \\
\hline \multirow[t]{3}{*}{3.} & \multirow[t]{3}{*}{ Responsiveness } & $\mathrm{X} 3.1$ & 0,894 & 0,361 & Valid \\
\hline & & X3.2 & 0,909 & 0,361 & Valid \\
\hline & & X3.3 & 0,890 & 0,361 & Valid \\
\hline \multirow[t]{3}{*}{4.} & \multirow[t]{3}{*}{ Assurance } & $\mathrm{X} 4.1$ & 0,841 & 0,361 & Valid \\
\hline & & $\mathrm{X} 4.2$ & 0,874 & 0,361 & Valid \\
\hline & & $\mathrm{X} 4.3$ & 0,898 & 0,361 & Valid \\
\hline \multirow[t]{3}{*}{5.} & \multirow[t]{3}{*}{ Empathy } & $\mathrm{X} 5.1$ & 0,913 & 0,361 & Valid \\
\hline & & $\mathrm{X} 5.2$ & 0,916 & 0,361 & Valid \\
\hline & & X5.3 & 0,944 & 0,361 & Valid \\
\hline \multirow[t]{3}{*}{6.} & \multirow[t]{3}{*}{ Kepuasan Pelanggan } & Y1.1 & 0,894 & 0,361 & Valid \\
\hline & & Y1.2 & 0,957 & 0,361 & Valid \\
\hline & & Y1.3 & 0,882 & 0,361 & Valid \\
\hline
\end{tabular}

Sumber: Data Primer yang diolah (2020)

Pada tabel 1, menunjukkan hasil validitas masing-masing variabel penelitian, dapat dilihat bahwa setiap pertanyaan dalam variabel memiliki $r$ hitung yang lebih besar dari $r$ tabel yang bernilai 0,361. Pada tabel tersebut juga ditunjukan bahwa variabel Tangible, Reliability, Responsiveness, Assurance, Empathy dan Kepuasan Pelanggan menunjukkan bahwa variabel tersebut dapat diterima dan tidak ada variabel yang harus dihilangkan karena hasil variabel-variabel tersebut valid. Berdasarkan hasil tersebut analisis penelitian dapat dilanjutkan.

2) Uji Reliabilitas

Pengujian ini sama halnya dengan uji validitas, yaitu dilakukan dengan program IBM Statistic Program for Social Science (SPSS) 25. Hasil uji reliabilitas dapat dilihat pada tabel 2. 
Tabel 2. Uji Reliabilitas

\begin{tabular}{|c|l|c|c|}
\hline No & \multicolumn{1}{|c|}{ Variabel } & Cronbach's Alpha & Keterangan \\
\hline 1. & Tangible & 0,866 & Reliabel \\
\hline 2. & Reliability & 0,882 & Reliabel \\
\hline 3. & Responsiveness & 0,879 & Reliabel \\
\hline 4. & Assurance & 0,830 & Reliabel \\
\hline 5. & Empathy & 0,910 & Reliabel \\
\hline 6. & Kepuasan Pelanggan & 0,896 & Reliabel \\
\hline
\end{tabular}

Sumber: Data Primer yang diolah (2020)

\section{c. Uji Asumsi Klasik}

1) Uji Multikolinearitas

Ghozali (2018:107) menjelaskan, bahwa uji multikolinearitas bertujuan untuk menguji apakah model regresi ditemukan adanya korelasi antar variabel bebas (independen). Uji Multikolinearitas mendeteksi ada atau tidaknya multikolinearitas di dalam model regresi dengan melihat nilai dari tolerance dan lawannya variance inflation factor (VIF). Jika nilai tolerance $\geq 0,10$ atau sama dengan nilai VIF $\leq 10$ maka tidak terjadi multikolinearitas.

Tabel 3. Hasil Uji Multikolinearitas

\begin{tabular}{|l|c|c|}
\hline \multicolumn{1}{|c|}{ Variabel } & Nilai Tolerance & Nilai VIF \\
\hline Tangible (X1) &, 581 & 1,721 \\
\hline Reliability (X2) &, 818 & 1,222 \\
\hline Responsiveness $(\mathrm{X} 3)$ &, 493 & 2,029 \\
\hline Assurance $(\mathrm{X} 4)$ &, 564 & 1,773 \\
\hline Empathy $(\mathrm{X} 5)$ &, 329 & 2,551 \\
\hline
\end{tabular}

Dependent Variable: Kepuasan Pelanggan (Y)

Sumber: Data Primer yang diolah (2020)

Berdasarkan tabel 3. dapat diketahui bahwa hasil perhitungan nilai tolerance menunjukkan variabel tangible, reliability, responsiveness, assurance, dan empathy memiliki nilai tolerance lebih dari 0,10 yang berarti tidak ada korelasi antar variabel independen. Hasil perhitungan nilai Variance Inflation Factor (VIF) juga menunjukkan hal yang sama yakni seluruh variabel independen memiliki nilai VIF kurang dari 10. Jadi dapat disimpulkan bahwa tidak terjadi multikolinearitas antar variabel independen dalam model regresi, artinya tidak ada hubungan antar variabel tangible, reliability, responsiveness, assurance, dan empathy.

2) Uji Heteroskedastisitas
Menurut Ghozali

(2018:137) menjelaskan, bahwa uji heteroskedastisitas bertujuan menguji apakah dalam sebuah model regresi, terjadi ketidaksamaan variance dari residual satu pengamatan ke pengamatan lain.

Deteksi ada atau tidaknya heteroskedastisitas dapat dilakukan dengan melihat ada tidaknya pola tertentu pada grafik scatterplot antara nilai prediksi variabel terikat (dependen) yaitu ZPRED dengan residualnya SRESID. Jika tidak ada pola yang jelas, serta titik-titik menyebar di atas dan di bawah angka 0 pada sumbu $\mathrm{Y}$, maka tidak terjadi heteroskedastisitas. Hasil uji heteroskedastisitas dapat dilihat pada gambar 2. 


\section{Gambar 2. Hasil Uji Heteroskedastisitas}

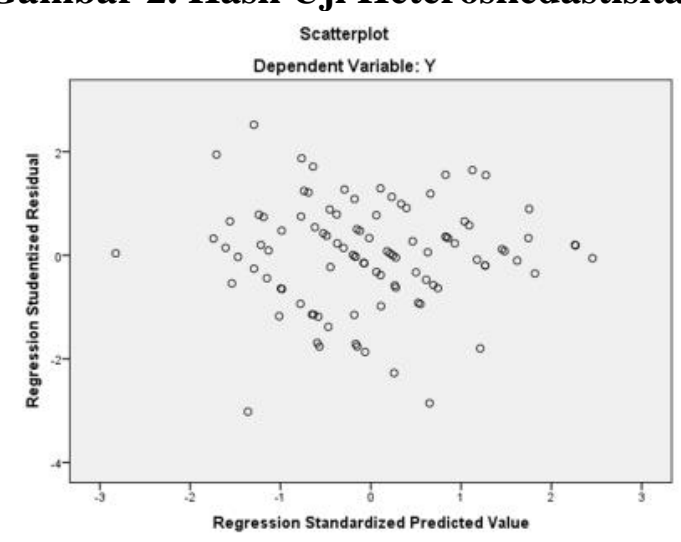

Sumber: Data Primer yang diolah (2020)

Berdasarkan gambar 2, terlihat bahwa titik menyebar di atas dan di bawah angka 0 pada sumbu Y. Titik tersebut juga tidak membentuk suatu pola tertentu, maka dapat dinyatakan bahwa tidak terjadi heteroskedastisitas.

3) Uji Normalitas
Menurut Ghozali (2018:161) uji normalitas bertujuan untuk mengetahui apakah dalam model regresi, variabel penganggu atau residual memiliki distribusi normal. Ada dua cara untuk mendeteksi apakah residual berdistribusi normal atau tidak yaitu dengan analisis grafik dan uji statistik Kolmogorov-Smirnov.

\section{Gambar 3. Histogram}

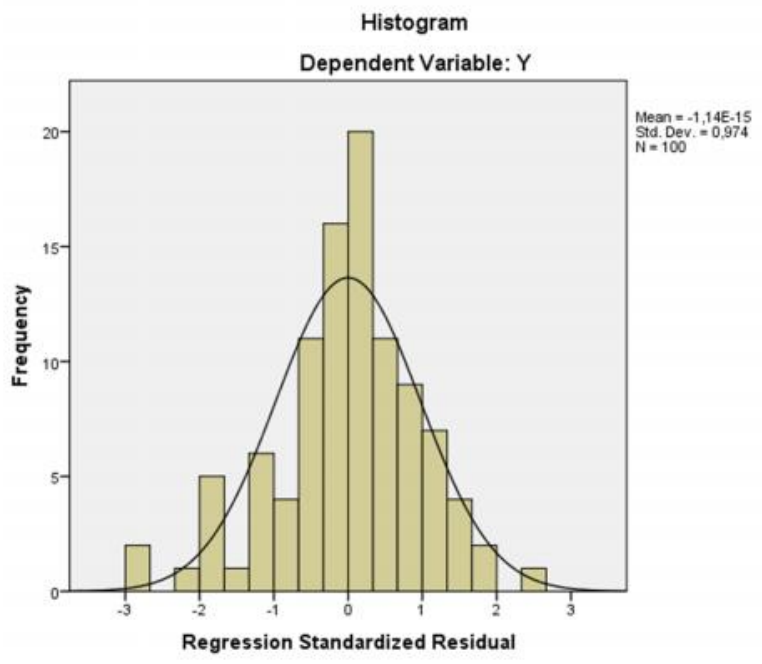

Sumber: Data Primer yang diolah, 2020 


\section{Gambar 4. Normal P-P Plot Of Regression Standarized Residual}

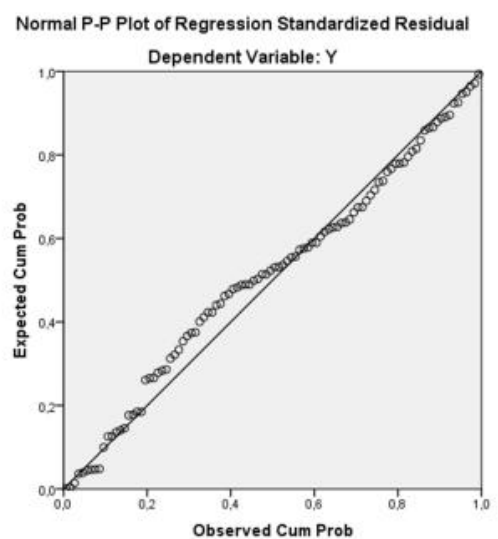

Sumber: Data Primer yang diolah (2020)

Pada gambar 4, disajikan hasil uji grafik plot dengan menggunakan SPSS 25. Dengan melihat grafik Gambar 4, dapat diketahui bahwa plot data menyebar di sekitar garis diagonal dan mengikuti arah garis diagonal. Dapat diartikan bahwa seluruh data dalam penelitian ini memiliki distribusi normal.

Pada Tabel 4, adalah hasil uji Kolmogorov-Smirnov dengan menggunakan SPSS 25:

Tabel 4. Hasil Uji Kolmogorov-Smirnov

\begin{tabular}{|c|c|}
\hline Variabel & Asymp. Signifikansi (2 tailed) \\
\hline Kepuasan Pelanggan & 0,103 \\
\hline
\end{tabular}

Sumber: Data Primer yang diolah (2020)

Berdasarkan uji Kolmogorov-Smirnov dapat diketahui bahwa nilai signifikansi sebesar 0,103 lebih besar dari 0,05, maka dapat disimpulkan bahwa semua data berdistribusi normal.

4) Uji Linearitas

Uji linearitas bertujuan untuk melihat spesifikasi model yang digunakan sudah benar atau belum (Ghozali, 2018:159). Konsep sederhana dari uji linearitas adalah untuk melihat apakah model regresi dapat didekati dengan persamaan linear. Model regresi dapat dikatakan memiliki hubungan yang linear apabila tingkat signifikansi (linearity) kurang dari 0,05 dan nilai deviation from linearity lebih dari 0,05. Apabila syarat tersebut sudah terpenuhi maka model regresi dapat dikatakan memiliki hubungan yang linear. Adapun hasil uji linearitas dalam penelitian ini dapat dilihat pada tabel 5 .

Tabel 5. Hasil Uji Linearitas

\begin{tabular}{|c|c|c|c|c|c|}
\hline No & Variabel & $\begin{array}{c}\text { Nilai } \\
\text { Signifikansi }\end{array}$ & Linearity & $\begin{array}{c}\text { Deviation from } \\
\text { Linearity }\end{array}$ & Keterangan \\
\hline 1 & $\mathrm{Y}^{* \mathrm{X} 1}$ & 0,05 & 0,000 & 0,244 & Linear \\
\hline 2 & $\mathrm{Y} \mathrm{X}^{2}$ & 0,05 & 0,000 & 0,457 & Linear \\
\hline 3 & $\mathrm{Y} \mathrm{X}^{*}$ & 0,05 & 0,000 & 0,500 & Linear \\
\hline 4 & $\mathrm{Y} \mathrm{X} 4$ & 0,05 & 0,000 & 0,900 & Linear \\
\hline 5 & $\mathrm{Y} * \mathrm{X} 5$ & 0,05 & 0,000 & 0,676 & Linear \\
\hline
\end{tabular}

Sumber: Data Primer yang diolah, 2020. 
Berdasarkan tabel di atas, dapat diketahui bahwa kelima variabel $\mathrm{X}$ dan Variabel Y dapat dikatakan memiliki hubungan yang linear. Hal tersebut dibuktikan dengan melihat nilai linearity lebih kecil dari nilai signifikansi sebesar 0,05 dan nilai deviation from linearity lebih dari 0,05.

\section{d. Analisis Regresi Linear Berganda}

Penelitian ini dilakukan untuk mengetahui seberapa besar pengaruh tangible (X1), reliability (X2), responsiveness (X3), assurance (X4), empathy (X5) terhadap kepuasan pelanggan (Y) pada Bengkel PT Wahana Sun Motor Semarang Cabang Puri Anjasmoro. Dihitung menggunakan analisis regresi linier berganda melalui program SPSS 25. Hasil analisis linier berganda dalam penelitian ini dapat dilihat pada tabel 6 .

Tabel 6. Hasil Analisis Regresi Linier Berganda

\begin{tabular}{|l|l|c|}
\hline \multicolumn{2}{|c|}{ Model } & $\begin{array}{c}\text { Unstandardized } \\
\text { Coefficients (B) }\end{array}$ \\
\hline \multirow{3}{*}{1} & (Constant) & $-2,425$ \\
\cline { 2 - 3 } & Tangible & 0,196 \\
\cline { 2 - 3 } & Reliability & 0,136 \\
\cline { 2 - 3 } & Responsiveness & 0,236 \\
\cline { 2 - 3 } & Assurance & 0,205 \\
\cline { 2 - 3 } & Empathy & 0,330 \\
\hline
\end{tabular}

Sumber: Data Primer yang diolah (2020)

Berdasarkan tabel 6, pada kolom Unstandardized Coefficients menunjukkan bahwa hasil koefisien regresi untuk variabel Tangible (X1) adalah sebesar 0,196, koefisien variabel Reliability (X2) sebesar 0,136, koefisien variabel Responsiveness (X3) sebesar 0,236, koefisien variabel Assurance (X4) sebesar 0,205, dan koefisien Empathy (X5) sebesar 0,330. Berdasarkan hasil data tersebut dapat dibentuk sebuah persamaan regresi yaitu:

$\mathrm{Y}=-2,425+0,196 \mathrm{X} 1+0,136 \mathrm{X} 2+0,236 \mathrm{X} 3$ $+0,205 \mathrm{X} 4+0,330 \mathrm{X} 5+\mathrm{e}$

Berdasarkan persamaan regresi berganda, hasil persamaan dapat dijelaskan sebagai berikut:

1) Konstanta (a) $=-2,425$

Konstanta sebesar -2,425 menunjukkan bahwa jika variabel independen yaitu tangible, reliability, responsiveness, assurance, dan empathy bernilai 0 (nol) maka variabel kepuasan pelanggan nilainya negatif sebesar $-2,425$, artinya pengaruh kelima variabel tersebut sangat penting untuk meningkatkan kepuasan pelanggan.

Nilai konstanta negatif pada hasil persamaan regresi linear berganda adalah -2,425. Menurut Maylina dan Ade (2017:101), skala likert yang digunakan tidak memasukkan angka 0 (nul), tetapi range dari angka 1-10, sehingga variabel $\mathrm{X}_{1}, \mathrm{X}_{2}, \mathrm{X}_{3}, \mathrm{X}_{4}$ dan $\mathrm{X}_{5}$ tidak mungkin sama dengan 0 (nul), karena itu konstanta negatif tersebut dapat diabaikan. Nurhidayati dan Kartika (2018:73) mengatakan bahwa konstanta negatif tidaklah menjadi persoalan dan bisa diabaikan selama model regresi sudah memenuhi asumsi, selama nilai slope tidak 0 (nul), maka tidak perlu memperdulikan konstanta negatif.

2) Koefisien Tangible (Bukti Fisik) $=0,196$ Hal ini menunjukkan bahwa variabel tangible berpengaruh positif terhadap kepuasan pelanggan pada bengkel PT Wahana Sun Motor Cabang Puri Anjasmoro. Setiap terjadi peningkatan pada variabel tangible sebesar 1 (satu) satuan, maka kepuasan pelanggan 
bengkel PT Wahana Sun Motor Cabang Puri Anjasmoro akan meningkat sebesar 0,196, dengan asumsi variabel lain tetap.

3) Koefisien Reliability (Kehandalan) = 0,136

Hal ini menunjukkan bahwa variabel reliability berpengaruh positif terhadap kepuasan pelanggan pada bengkel PT Wahana Sun Motor Cabang Puri Anjasmoro. Setiap terjadi peningkatan pada variabel reliability sebesar 1 (satu) satuan, maka kepuasan pelanggan bengkel PT Wahana Sun Motor Cabang Puri Anjasmoro akan meningkat sebesar 0,136, dengan asumsi variabel lain tetap.

4) Koefisien Responsiveness (Daya Tanggap) $=0,236$

Hal ini menunjukkan bahwa variabel responsiveness berpengaruh positif terhadap kepuasan pelanggan pada bengkel PT Wahana Sun Motor Cabang Puri Anjasmoro. Setiap terjadi peningkatan pada variabel responsiveness sebesar 1 (satu) satuan, maka kepuasan pelanggan bengkel PT Wahana Sun Motor Cabang Puri Anjasmoro akan meningkat sebesar 0,236, dengan asumsi variabel lain tetap.

5) Koefisien Assurance (Jaminan) $=0,205$

Hal ini menunjukkan bahwa variabel assurance berpengaruh positif terhadap kepuasan pelanggan pada bengkel PT Wahana Sun Motor Cabang Puri Anjasmoro. Setiap terjadi peningkatan pada variabel assurance sebesar 1 (satu) satuan, maka kepuasan pelanggan bengkel PT Wahana Sun Motor Cabang Puri Anjasmoro akan meningkat sebesar 0,205, dengan asumsi variabel lain tetap.

6) Koefisien Empathy (Empati) = 0,330 Hal ini menunjukkan bahwa variabel empathy berpengaruh positif terhadap kepuasan pelanggan pada bengkel PT Wahana Sun Motor Cabang Puri Anjasmoro. Setiap terjadi peningkatan pada variabel empathy sebesar 1 (satu) satuan, maka kepuasan pelanggan bengkel PT Wahana Sun Motor Cabang Puri Anjasmoro akan meningkat sebesar 0,330, dengan asumsi variabel lain tetap.

\section{e. Uji Hipotesis}

1) Koefisien Determinasi $\left(R^{2}\right)$

Menurut Ghozali (2018:97) koefisien determinasi $\left(\mathrm{R}^{2}\right)$ pada intinya mengukur seberapa jauh kemampuan model dalam menerangkan variasi variabel dependen.

Hasil analisis koefisien determinasi dapat dilihat pada tabel 7.:

Tabel 7. Hasil Uji Koefisien Determinasi

\begin{tabular}{|c|c|}
\hline Model & Adjusted $R$ Square \\
\hline 1 & 0,603 \\
\hline \multicolumn{2}{|c|}{ Sumber: Data Primer yang diolah (2020) }
\end{tabular}

Berdasarkan tabel 7, dapat diketahui bahwa nilai koefisien determinasi (Adjusted $R$ Square) sebesar 0,603 atau 60,3\%. Hal tersebut dapat disimpulkan bahwa variabel Tangible, Reliability, Responsiveness, Assurance, dan Empathy memberikan kontribusi pengaruh terhadap kepuasan pelanggan sebesar $60,3 \%$. Sedangkan sisanya sebesar $39,7 \%$ kepuasan pelanggan dipengaruhi oleh variabel lain yang tidak diteliti dalam penelitian ini.
2) Uji Signifikansi Simultan (Uji F) Menurut Ghozali (2018:98) uji F digunakan untuk mengetahui variabel independen secara bersama-sama atau simultan mempengaruhi variabel dependen. Cara pengujiannya, apabila $f_{\text {hitung }}>f_{\text {tabel }}$ atau signifikansi kurang dari 0,05 maka $\mathrm{H}_{0}$ ditolak dan $\mathrm{H}_{\mathrm{a}}$ diterima begitu juga sebaliknya. Hasil uji f dapat dilihat pada tabel 8 . 
Tabel 8. Hasil Uji Signifikansi Simultan (Uji F)

\begin{tabular}{|r|r|r|}
\hline Model & F & Sig \\
\hline Regresi & 31,104 & 0,000 \\
\hline
\end{tabular}

Sumber: Data Primer yang diolah, 2020.

Dari tabel 8, diperoleh nilai signifikansi sebesar 0,000, $F_{\text {hitung }}$ sebesar 31,104 dan diperoleh $f_{\text {tabel }}$ sebesar 2,31. Dari hasil uji $\mathrm{f}$ diperoleh $\mathrm{f}_{\text {hitung }}(31,104)>\mathrm{f}_{\text {tabel }}$ $(2,31)$ dan signifikansi $0,000<0,05$. Hal ini menunjukkan bahwa $\mathrm{H}_{0} 6$ ditolak dan $\mathrm{H}_{\mathrm{a}} 6$ diterima. Sehingga dapat dikatakan bahwa tangible, reliability, responsiveness, assurance, empathy secara bersama-sama berpengaruh secara signifikan terhadap kepuasan pelanggan. Tangible, reliability, responsiveness, assurance, empathy meningkat, maka kepuasan pelanggan juga mengalami peningkatan. Sebaliknya, apabila tangible, reliability, responsiveness, assurance, empathy mengalami penurunan, maka kepuasan pelanggan juga akan menurun.

3) Uji Signifikansi Parsial (Uji T)

Pada dasarnya menunjukan seberapa jauh pengaruh satu variabel penjelas/independen secara individual dalam menerangkan variasi variabel dependen (Ghozali, 2018:23). Ketentuan dalam uji t adalah sebagai berikut:

a) Ha diterima apabila $t_{\text {hitung }}>t_{\text {tabel }}$ Ha diterima apabila sig $<0,05$

b) Ha ditolak apabila $t_{\text {hitung }}<t_{\text {tabel }}$ Ha ditolak apabila sig $>0,05$

Hasil uji $\mathrm{t}$ dalam penelitian ini dapat dilihat pada tabel 9:

Tabel 9. Hasil Uji Signifikansi Parsial (Uji T)

\begin{tabular}{|l|c|c|}
\hline Model & T & Sig. \\
\hline Tangible (X1) & 2,018 & 0,046 \\
\hline Reliability (X2) & 2,013 & 0,047 \\
\hline Responsiveness (X3) & 2,368 & 0,020 \\
\hline Assurance (X4) & 2,107 & 0,038 \\
\hline Empathy (X5) & 3,065 & 0,003 \\
\hline
\end{tabular}

Sumber: Data Primer yang diolah (2020)

Berdasarkan tabel 9, hasil uji statistik t dapat dilakukan pembuktian hipotesis terhadap masing-masing variabel sebagai berikut:

a) Pembuktian Hipotesis 1

Pembuktian hipotesis 1 (satu) dilakukan dengan uji statistik t. Berdasarkan tabel di atas dihasilkan $t_{\text {hitung }}$ untuk variabel tangible (bukti fisik) $=2,018>\mathrm{t}_{\text {tabel }}=$ 1,984 atau signifikansi $=0,046<0,05$ yang berarti terdapat pengaruh yang signifikan antara tangible secara parsial terhadap kepuasan pelanggan. Hipotesis 1 (satu) yang menyatakan "Terdapat pengaruh antara tangible terhadap kepuasan pelanggan pada bengkel PT
Wahana Sun Motor Cabang Puri Anjasmoro" dinyatakan diterima.

b) Pembuktian hipotesis 2

Pembuktian hipotesis 2 (dua) dilakukan dengan uji statistik t. Berdasarkan tabel di atas dihasilkan $t_{\text {hitung }}$ untuk variabel reliability (kehandalan) $=2,013>\mathrm{t}_{\text {tabel }}=$ 1,984 atau signifikansi $=0,047<0,05$ yang berarti terdapat pengaruh yang signifikan antara reliability secara parsial terhadap kepuasan pelanggan. Dengan demikian hipotesis 2 (dua) yang menyatakan "Terdapat pengaruh antara reliability terhadap kepuasan pelanggan pada bengkel PT Wahana Sun Motor Cabang Puri Anjasmoro" dinyatakan diterima. 
c) Pembuktian hipotesis 3

Pembuktian hipotesis 3 (tiga) dilakukan dengan uji statistik t. Berdasarkan tabel diatas dihasilkan $t_{\text {hitung }}$ untuk variabel responsiveness (daya tanggap) $=2,368>$ $\mathrm{t}_{\text {tabel }}=1,984$ atau signifikansi $=0,020<$ 0,05 yang berarti terdapat pengaruh yang signifikan antara responsiveness secara parsial terhadap kepuasan pelanggan. Dengan demikian hipotesis 3 (tiga) yang menyatakan "Terdapat pengaruh antara responsiveness terhadap kepuasan pelanggan pada bengkel PT Wahana Sun Motor Cabang Puri Anjasmoro" dinyatakan diterima.

d) Pembuktian hipotesis 4

Pembuktian hipotesis 4 (empat) dilakukan dengan uji statistik t. Berdasarkan tabel di atas dihasilkan $t_{\text {hitung }}$ untuk variabel assurance (jaminan) = $2,107>\mathrm{t}_{\text {tabel }}=1,984$ atau signifikansi $=$ $0,038<0,05$ yang berarti terdapat pengaruh yang signifikan antara assurance secara parsial terhadap kepuasan pelanggan. Dengan demikian hipotesis 4 (empat) yang menyatakan "Terdapat pengaruh antara assurance terhadap kepuasan pelanggan pada bengkel PT Wahana Sun Motor Cabang Puri Anjasmoro" dinyatakan diterima.

e) Pembuktian hipotesis 5

Pembuktian hipotesis 5 (lima) dilakukan dengan uji statistik t. Berdasarkan tabel di atas dihasilkan $t_{\text {hitung }}$ untuk variabel empathy $($ empati $)=3,065>\mathrm{t}_{\text {tabel }}=1,984$ atau signifikansi $=0,003<0,05$ yang berarti terdapat pengaruh yang signifikan antara empathy secara parsial terhadap kepuasan pelanggan. Dengan demikian hipotesis 5 (lima) yang menyatakan "Terdapat pengaruh antara empathy terhadap kepuasan pelanggan pada bengkel PT Wahana Sun Motor Cabang Puri Anjasmoro" dinyatakan diterima.

\section{KESIMPULAN}

Berdasarkan hasil penelitian mengenai pengaruh kualitas pelayanan (tangible, reliability, responsiveness, assurance dan empathy) terhadap kepuasan pelanggan bengkel PT Wahana Sun Motor Cabang Puri Anjasmoro dapat disimpulkan bahwa:

a. Tangible (Bukti Fisik) berpengaruh positif dan signifikan terhadap kepuasan pelanggan bengkel PT Wahana Sun Motor Cabang Puri Anjasmoro dengan nilai $t_{\text {hitung }}>\mathrm{t}_{\text {tabel }}(2,018>1,985)$ dan nilai signifikansi $0,046<0,05$ serta nilai koefisien regresi sebesar 0,196. Diartikan bahwa semakin tinggi tingkat tangible (bukti fisik) dalam memberikan pelayanan, maka kepuasan pelanggan juga akan semakin tinggi. Sebaliknya, apabila tingkat bukti fisik rendah, maka kepuasan pelanggan pun rendah.

b. Reliability (kehandalan) berpengaruh positif dan signifikan terhadap kepuasan pelanggan bengkel PT Wahana Sun Motor Cabang Puri Anjasmoro dengan nilai $t_{\text {hitung }}>t_{\text {tabel }}(2,013>1,985)$ dan nilai signifikansi $(0,047<0,05)$ serta nilai koefisien regresi sebesar 0,136 . Hal ini membuktikan bahwa meningkatnya penerapan reliability (kehandalan) yang dilakukan oleh karyawan bengkel akan membuat kepuasan pelanggan juga meningkat. Sebaliknya, apabila reliability (kehandalan) menurun, maka kepuasan pelanggan pun ikut menurun.

c. Responsiveness (daya tanggap) berpengaruh positif dan signifikan terhadap kepuasan pelanggan bengkel PT Wahana Sun Motor Cabang Puri Anjasmoro dengan nilai $t_{\text {hitung }}>t_{\text {tabel }}$ $(2,368>1,985)$ dan nilai signifikansi $(0,020<0,05)$ serta nilai koefisien regresi sebesar 0,236. Semakin tinggi responsiveness (daya tanggap) dalam pelayanan, maka kepuasan pelanggan juga semakin tinggi. Sebaliknya, apabila responsiveness (daya tanggap) rendah, maka kepuasan pelanggan pun rendah.

d. Assurance (jaminan) berpengaruh positif dan signifikan terhadap kepuasan pelanggan bengkel PT Wahana Sun Motor Cabang Puri Anjasmoro dengan 
nilai $t_{\text {hitung }}>\mathrm{t}_{\text {tabel }}(2,107>1,985)$ dan nilai signifikansi $(0,038<0,05)$ serta nilai koefisien regresi sebesar 0,205. Hal ini membuktikan bahwa meningkatnya penerapan assurance (jaminan) yang dilakukan oleh karyawan bengkel akan membuat kepuasan pelanggan juga meningkat. Sebaliknya, apabila assurance (jaminan) menurun, maka kepuasan pelanggan pun ikut menurun.

e. Empathy (Empati) berpengaruh positif dan signifikan terhadap kepuasan pelanggan bengkel PT Wahana Sun Motor Cabang Puri Anjasmoro dengan nilai $t_{\text {hitung }}>t_{\text {tabel }}(3,065>1,985)$ dan nilai signifikansi $(0,003<0,05)$ serta nilai koefisien regresi sebesar 0,330 . Hal ini membuktikan bahwa meningkatnya penerapan empathy (empati) yang dilakukan oleh karyawan bengkel akan membuat kepuasan pelanggan juga meningkat. Sebaliknya, apabila empathy (empati) menurun, maka kepuasan pelanggan pun ikut menurun.

\section{Saran}

Berdasarkan hasil penelitian diketahui bahwa kualitas pelayanan berpengaruh terhadap kepuasan pelanggan. Kualitas pelayanan bengkel PT Wahana Sun Motor Cabang Puri Anjasmoro sudah baik namun masih dapat ditingkatkan lagi. Saran yang dapat dijadikan masukan untuk bengkel PT Wahana Sun Motor Cabang Puri Anjasmoro antara lain:

a. Bengkel PT Wahana Sun Motor Cabang Puri Anjasmoro sebaiknya lebih memberikan perhatian terhadap kenyamanan ruang tunggu, seperti disediakannya snack yang lebih bervariasi, coffe corner, high speed wifi, dan AC yang lebih 'dingin akan membuat pelanggan lebih nyaman saat menunggu servis.

b. Karyawan bengkel PT Wahana Sun Motor Cabang Puri Anjasmoro agar memperhatikan lagi ketepatan waktu dalam melayani pengunjung sehingga pelayanan dapat diselesaikan tepat waktu dan pengunjung tidak perlu untuk menunggu lama.

c. Karyawan bengkel PT Wahana Sun Motor Cabang Puri Anjasmoro seharusnya memberikan informasi yang akurat. Informasi yang akurat sangat dibutuhkan bagi pelanggan untuk mengatasi keluhan yang dihadapi pelanggan, oleh karena itu karyawan harus memiliki pengetahuan yang baik mengenai dunia otomotif, agar informasi yang diberikan lebih akurat.

d. Bengkel PT Wahana Sun Motor Cabang Puri Anjasmoro perlu meningkatkan kecepatan memahami kebutuhan pelanggan. Memberikan arahan atau bimbingan secara personal kepada karyawan mengenai bagaimana menangani kebutuhan pelanggan dengan baik. Memberikan informasi mengenai kebutuhan apa saja yang biasanya dibutuhkan pelanggan, sehingga dapat mengingkatkan kecepatan karyawan dalam memahami kebutuhan pelanggan.

e. Responden yang digunakan dalam penelitian ini hanya pelanggan PT Wahana Sun Motor Cabang Puri Anjasmoro yang berada di wilayah Semarang saja. Tidak digeneralisasi untuk obyek lain selain di PT Wahana Sun Motor Cabang Puri Anjasmoro. Saran bagi penelitian selanjutnya agar model penelitian ini dapat diujikan terhadap obyek lain seperti PT Wahana Sun Motor Cabang Majapahit, PT Wahana Sun Motor Cabang Setiabudi atau cabang lainnya.

\section{DAFTAR PUSTAKA}

Alaan, Yunus. 2016. "Pengaruh Service Quality (Tangible, Empathy, Reliability, Responsiveness, dan Assurance) terhadap Customer Satisfaction: Penelitian pada hotel Selera Bandung. Jurnal Manajemen. Volume 15, Nomor 2. Bandung 
Bhatta, K.R., \& Bhanu P.D. 2016. Service Quality Perception and Customer Satisfaction In Nepalese Banking Sector.Indian Journal of Commerce and Management Studies, 7(1), 17-23, Retrieved from https://search.proquest.com/doctview/183 0724553 ? accountid $=40625$

Elmelegy, A. R. dkk. 2017. Antecedents Of Hypermarket Service Quality In The United Arab Emirates. The Quality Management Journal, 24(4), 35. Retrieved from https://search.proquest.com/docview/195 1916696 ? accountid $=40625$

Ferdinand, Augusty, 2014. Metode Penelitian Manajemen Pedoman Penelitian untuk Penulisan Skripsi, Tesis dan Disertasi. Semarang: Badan Penerbit Universitas Diponegoro

Firdiyansyah, Indra. 2017. "Pengaruh Kualitas Pelayanan, Harga, dan Lokasi Terhadap Kepuasan Pelanggan pada Warung Gubrak Kepri Mall Kota Batam”. Ejournal stiegalileo. Volume 1, Nomor 1, Kota Batam.

Ghozali, Imam. 2018. Aplikasi Analisis Multivariete Dengan Program IBM SPSS 25. Semarang: Badan Penerbit Universitas Diponegoro.

Irawan, Handi. 2008. Indonesia Customer Satisfaction. Jakarta: PT. Alex Media Computindo.

Janahi, M.A. and Muneer M.S.A.M. 2017. "The impact of customer service quality on customer satisfaction in Islamic banking". Journal of Islamic Marketing, Vol. 8 No. 4, pp. 595604. https://doi.org/10.1108/JIMA-072015-0049

Kant, Rishi dkk. 2017. The investigation of service quality dimensions, customer satisfaction and corporate image in Indian Public Sector Bank. Journal of Business Perspective, https://doi.org/10.1177/09722629166812 56.
Kerin, Roger A dan Steven W. Hartley. 2016. Marketing, Thirteenth Edition. New York: McGraw-Hill Education

Kotler, Philip T. dan Gary Armstrong. 2017. Principle of Markting Seventeenth Edition Global Edition. Italy: Lego

Kotler, Philip T. dan Kevin Lane Keller. 2018. Management Marketing Fifteenth Edition. United States of America: Courier/Kendallville

Kotler, Philip T. dkk. 2017. Marketing An Asian Perpective Fouth Edition. Malaysia: Vivar

Lupiyoadi, Rambat. 2009. Manajemen Pemasaran Jasa. Jakarta: Salemba Empat

Masrurul, M. M. (2019). Investigating the compliance of tourism principles with the components of sustainable tourism: Bangladesh perspective. Advances in Management, 12(1), 4-7. Retrieved from https://search.proquest.com/docview/218 7373983 ? accountid $=40625$

Mayefis, Delladari dkk. (2017). "Pengaruh kualitas pelayanan informasi obat terhadap kepuasan pasien apotek x kota Padang." Jurnal ilmu kefarmasian Indonesia 13.2: 201-204

Maylina, Deti, and Ade Sofyan Mulazid. Analisis pengaruh service quality, customer relationship management dan keunggulan produk tabungan terhadap loyalitas nasabah pada Bank BRI Syariah. BS thesis. Jakarta: Fakultas Ekonomi dan Bisnis UIN Syarif Hidayatullah Jakarta, 2017.

Naderian, Anahita dan Rohaizat Baharun. (2015). Service quality and consumer satisfaction and loyalty association moderated by switching cost in hospitality industry. International Journal of Hospitality and Tourism Systems, 8(1) Retrieved from https://search.proquest.com/docview/173 $\underline{3224750 \text { ? accountid }=40625} \quad(18 \quad$ Mei 2020)

Nguyen, Quang dkk. 2018. Understanding customer satisfaction in the UK quick service restaurant industry. British Food 
Journal, $\quad$ 120(6), 1207-1222. Doi:http://dx.doi.org/10.1108/BFJ-082017-0449 (20 April 2020)

Nugroho, Aji dan Rizal Hari Magnadi. 2018. Pengaruh Kualitas Layanan Terhadap Kepuasan Pelanggan Jasa Pengiriman Lazada Express Saat Harbolnas di ECommerce. Diponegoro Journal of Management.7(4):1-11

Nurhidayati, and Kartika Yuliantari. 2018. Analisis Pengaruh Kepuasan Pelanggan terhadap Loyalitas Pelanggan pada Fish Streat Cabang Tebet. Widya Cipta: Jurnal Sekretari dan Manajemen 2.1: 6975.

Panjaitan, Januar Efendi dan Ai Lili Yuliati. 2016. "Pengaruh Kualitas Pelayanan terhadap Kepuasan Pelanggan pada JNE Cabang Bandung". DeReMa Jurnal Manajemen Volume 11, Nomor 2. Bandung

Permansari, Ragil. 2013. Pengaruh Motivasi dan Lingkungan Kerja terhadap Kinerja PT Anugrah Raharjo Semarang. Management Analysis Journal 2 (2)

Rifaldi, Kadunci dan Sulistyowati. 2016. Pengaruh Kualitas Pelayanan Transportasi Gojek terhadap Kepuasan Pelanggan pada Mahasiswa/i Administrasi Niaga Politeknik Negeri Jakarta. Epigram Vol. 13 No.2.

Rizqy, RR Rien dkk. 2016. "Pengaruh Kualitas Pelayanan terhadap Kepuasan Konsumen (Studi Kasus pada konsumen PT. Graha Service Indonesia Cabang Semarang)." Journal of Management 2.2

Rohaeni, Heni dan Nisa Marwa. 2018. Kualitas Pelayanan terhadap Kepuasan Pelanggan. Jurnal Ecodemica Vol 2, No.2.

Sari, Elina. 2019. Pengaruh Kualitas Pelayanan Terhadap Kepuasan Pelanggan pada Badan Penyelenggara Jaminan Sosial (BPJS) Ketenagakerjaan Cabang Ungaran. Tugas Akhir
Sugiyono. 2017. Metode Penelitian Kuantitatif, Kualitatif dan R\&D. Bandung: ALFABETA

Sujarweni, V. Wiratna. 2019. Metodologi Penelitian Bisnis \& Ekonomi. Yogyakarta: PUSTAKABARUPRESS

Tabaku, Elvira dan Shpetim Cerri. 2016. An Assessment Of Service Quality And Customer Satisfaction In The Hotel Sector.Faculty of Tourism and Hospitality Management in Opatija.Biennial International Congress. Tourism\&Hospitality Industry. 480 489. Retrieved from https://search.proquest.com/doctview/180 $\underline{6211092 \text { ?accountid }=40625} \quad(18 \quad$ Mei 2020)

Tiza, Mohd Farid dan Febsri Susanti. 2019. Pengaruh Kualitas Pelayanan terhadap Kepuasan Pelanggan Studi Kasus pada Perusahaan JNE Cabang Padang. https://doi.org/10.31227/osf.io/hx87m

Tjiptono, Fandy. 2002. Strategi Pemasaran Jasa. Yogyakarta: ANDI.

2014. Pemasaran

Jasa:Prinsip, Penerapan, dan Penelitian. Yogyakarta: ANDI.

Tjiptono, Fandy dan Gregorius Candra. 2016. Service, Quality, dan Satisfaction. Yogyakarta: ANDI.

Ulfa, Mailani, and Riri Mayliza. 2020. "Pengaruh Kualitas Pelayanan dan Kepuasan Pelanggan terhadap Loyalitas Pelanggan PDAM Kota Padang."

Wahyuni, Hana Catur dkk. 2015. Pengendalian Kualitas; Aplikasi pada Industri Jasa dan Manufaktur dengan Lean, Six Sigma dan Servqual. Yogyakarta: Graha Ilmu.

Wirtz, Jochen dkk. 2017. Essentials of Services Marketing 3rd Edition. Italy: L.E.G.O.S.p.A.Lavis (TN)

Zeithaml, Valarie A. dkk. 2017. Services Marketing Integrating Customer Focus Across The Firm, Seventh Edition. New York: McGraw-Hill Education 